\title{
APPLICATION OF THE RISK ASSESSMENT METHODS OF RAILWAY TRANSPORT IN ESTONIAN OIL SHALE INDUSTRY
}

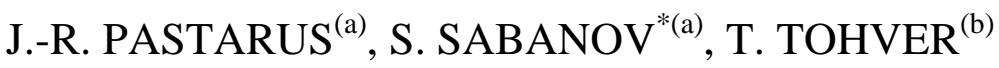 \\ (a) Department of Mining, Tallinn University of Technology \\ 5 Ehitajate Rd., 19086 Tallinn, Estonia \\ (b) Estonian Oil Shale Company \\ 10 Jaama Str., 41533 Jõhvi, Estonia
}

\begin{abstract}
The paper deals with risk analysis/assessment problems in Estonian oil shale industry. Investigations are focused on application of these methods for railway transport from mine to consumer. Various factors relevant to oil shale transport have been determined. For risk estimation an empirical approach, the eventffault tree is used. It allows to determine probability of deviations of the process duration from the mean value for different pathways. The obtained information affords specialists to improve the quality of the railway transport. The analysis shows that the used method is applicable in conditions of Estonian railway systems. The results of the investigation are of particular interest for practical purposes.
\end{abstract}

\section{Introduction}

In Estonia a specific kind of oil shale kukersite is the most important mineral resource. Oil shale reserves are estimated to be approximately four billion tonnes. $85 \%$ of mined oil shale is used for generation of electric power and a large share of thermal power, and about $15 \%$ goes for shale oil production. Oil shale industry of Estonia provides a significant contribution to the country's economy, but economically viable transportation of oil shale to consumers is impossible without advanced railway network. Railway transportation of oil shale is indispensable. It is cheap and highly productive.

Transportation of oil shale from mines and open casts to consumers causes a lot of technical and economical problems. Conventional theoretical basis does not allow to solve these problems. Available data give a good basis for elaboration of the concept and methods of risk analysis/assessment. The results can be used to solve the problems of transportation.

\footnotetext{
* Corresponding author: e-mail sergei.sabanov@mail.ee
} 
This study addresses the risks associated with oil shale loading and transportation, evaluation of the usability of the method and estimation of the probability of failure without detailed assessment of its consequences being the primary objects of interest. The study is based on the literature and on the Estonian experience. As an example, the risk analysis/assessment method has been applied to study transportation in Estonian oil shale mines. To simplify this task, the track between the stations Musta, Raudi (Estonia mine) and Musta was considered.

Risk assessment/management involves judgments about taking a risk, at which all parties must recognize the possibility of adverse consequences which might materialize $[1,2]$. Prevention of hazardous situations is more moral, ethical and economical than facing the adverse consequences. Risk assessment method gives information about the transportation system. The information obtained could help the management of the mining company to come to adequate political and strategic decisions. The concept and methods of risk analysis/assessment can be used for different purposes and at different levels: at the stage of transport system design; as the basis for decision-making when choosing between different remedial actions for transportation system within temporal and financial restraints [1]. The risk analysis/assessment method is the most powerful tool for solving complicated mining problems.

Risk analysis involves the use of available information to provide the transportation system for a risk. Various factors relevant to oil shale transportation are determined in the present study. Probable risk analysis is a more rational basis for evaluation. The event/fault tree is used for risk estimation. Having obtained the risk information and knowing the risk evaluation criteria, we come to a decision.

The analysis shows that the risk analysis/assessment methods used are applicable for transportation systems. The results of the risk assessment are of particular interest to be used in practice.

\section{Theoretical background}

In Estonia, like in other countries, risk management methods are used in different branches of industry and for many different technical systems. Irrespective of terminology, there is a general agreement on the basic requirements $[1,3,4]$. Terminology and risk management method used in the frame of this project are presented below.

Risk management is systematic application of the management policies, procedures and practices for identifying, analyzing, assessing, treating and monitoring the risk $[1,4]$. Having obtained the risk information, a decisionmaker must come to a decision. The primary steps of the risk management are presented in Fig. 1. 


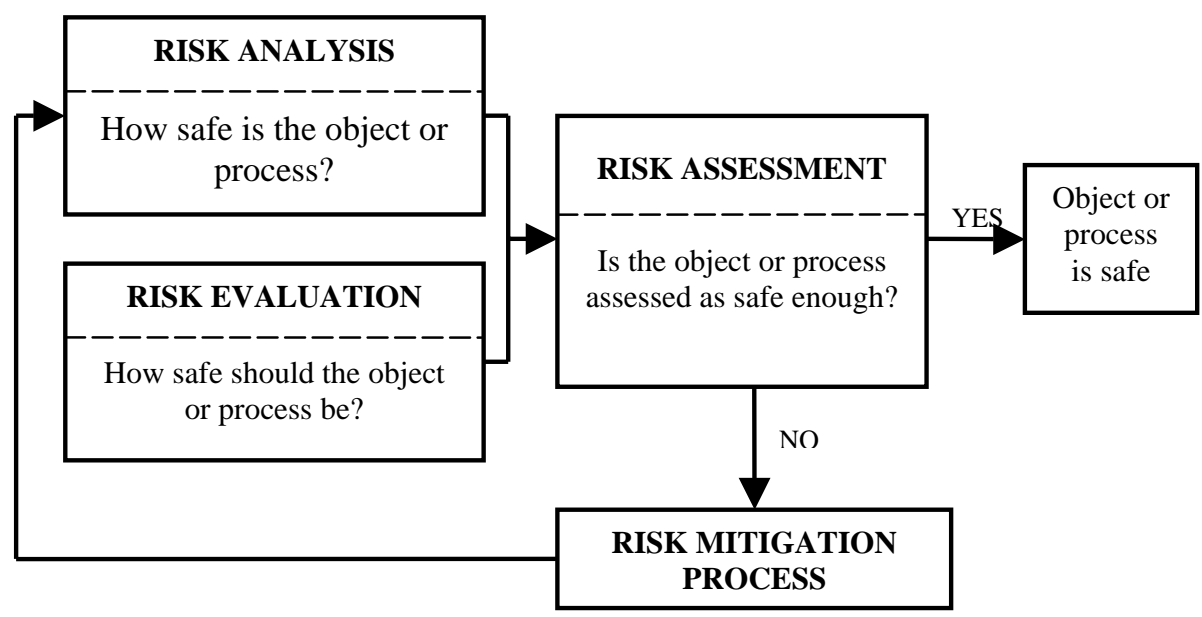

Fig. 1. Risk management process

Risk assessment is the process of deciding whether existing risks are tolerable and risk control measures adequate [1,4]. It involves making judgments about taking the risk (whether the object or process is assessed as safe enough), and all parties must recognize that the adverse consequences might materialize, and owners will be required to deal effectively with the consequences of the failure event. Risk assessment incorporates the risk analysis and risk evaluation phases.

Risk analysis is the process of determining how safe the object or process is. Risk analysis contains the following steps: scope definition, hazard identification, and risk estimation. The description of the system, scope and expectations of risk analysis should be defined at the outset. An iterative approach should be adopted with qualitative methods being employed at the early stages of the process. If more information becomes available, the use of quantitative analysis is required.

Risk identification is the process of determining what can go wrong, why and how. Failure can be described at many different levels. Conceptualization of different possible failure modes for a technical system is an important part of risk identification. At first, as many types of failure as possible should be taken into account. The initial list can then be reduced by eliminating those types of failures which are considered implausible.

Risk estimation entails the assignment of probabilities to the events and responses identified under risk identification. The assessment of the appropriate probability estimates is one of the most difficult tasks of the entire process. Fault/event trees [1] are the tools often used in risk estimation. Probability estimation can be performed according to three general approaches depending on the type and quality of the available data: 
1. Analytical approach uses logical models to calculate probabilities.

2. Empirical approach uses existing databases to establish probability.

3. Judgmental approach uses the experience of practical engineers in guiding the estimation of probabilities.

Attaining an exact value of probability at examining technical systems and processes is not a realistic expectation.

Risk evaluation is the process of examining and judging the significance of risk. It must answer the question how safe the process or object should be. It is based on the available information, including consideration of the importance of the estimated risks and the associated social, environmental and economic consequences. The principal role of risk evaluation in risk assessment is the generation of decision guidance against which the results of risk analysis can be assessed.

Risk acceptance is an informed decision to accept the likelihood and the consequences of a particular risk. In some countries, there is a certain risk level which is defined as the limit of unacceptable risk. For failure events with no potential fatalities or irreparable damage to the environment, the target failure probability may be decided exclusively basing on economic considerations and corresponding risk analysis [2].

Risk mitigation is a selective application of appropriate techniques and management principles to reduce either likelihood of an occurrence or its consequences, or both [1, 3-5]. If the calculated risk of the existing system is judged to be too high, alternatives are proposed to reduce the risk of failure. After repeated study the decision-makers can be provided with suitable alternatives and their estimated costs for consideration in improving overall technical system safety.

\section{Applicability of risk analysis/assessment methods in mining}

Worldwide experience has shown that the risk analysis/assessment method is a very powerful tool to solve complicated industrial problems. Conventional theories do not enable to solve these tasks. In the world the risk analysis/ assessment methods are used in different branches of industry, but the number of references on solution of mining problems is limited. Investigations have shown that the above-mentioned methods are applicable for solving complicated mining problems. All underground and surface processes in a mine are presented in Fig. 2.

One can see that the stages of the mining process are at different levels and of different importance. Each process will be subjected to risk analysis/ assessment. The very important tertiary process on the surface - transportation of minerals (oil shale) from Estonia mine to the consumer - was chosen to carry out the risk analysis. 


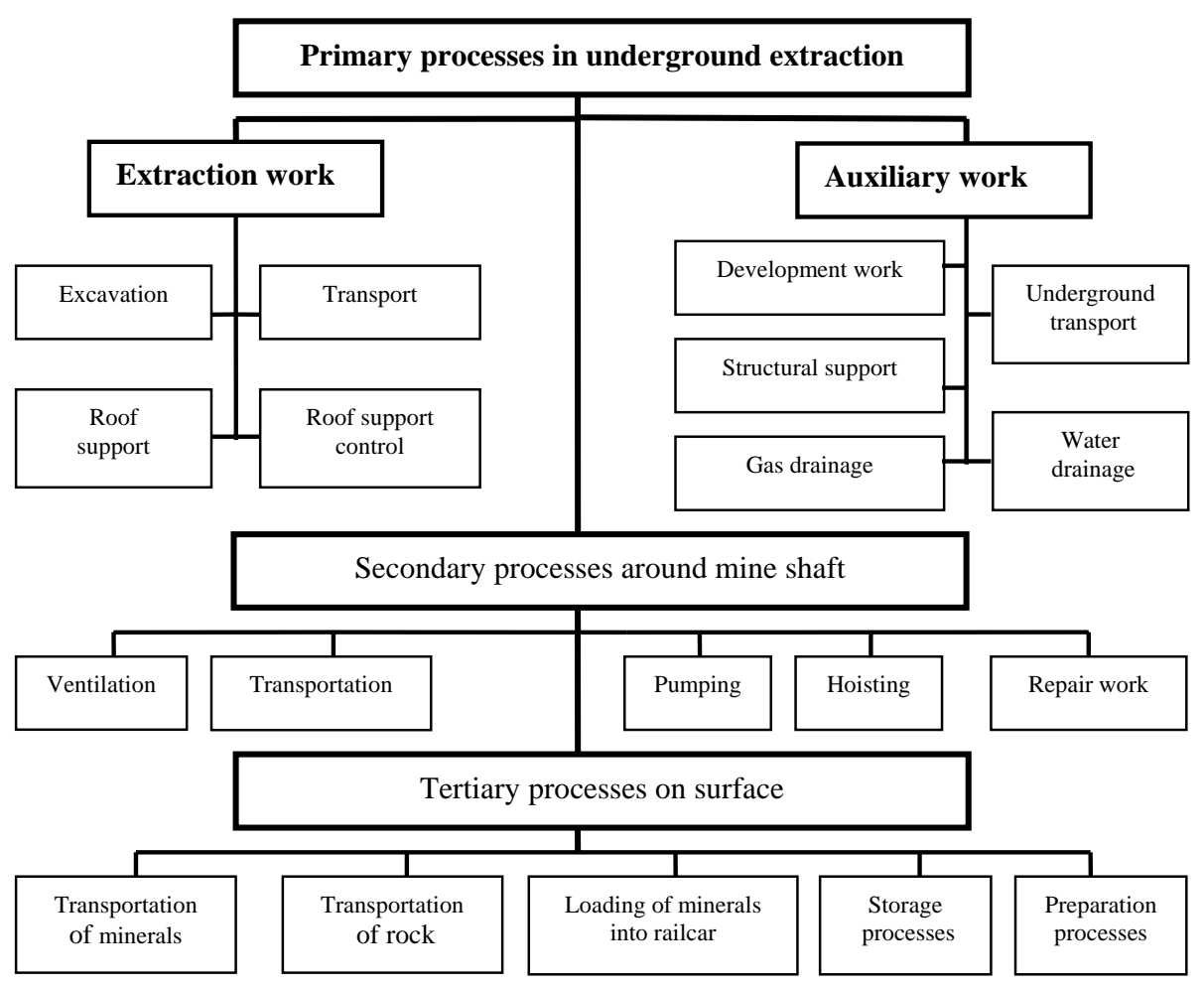

Fig. 2. Processes involved in underground mining

\section{Network of railways}

The network of railways between the mines, open casts and consumers is complicated. To simplify the task, the track between the stations Musta, Raudi (Estonia mine) and Musta was considered (Fig. 3).

Cars are unloaded at Musta station. An empty train unit comes from Musta station to Raudi station (Estonia mine) where the oil shale loading process takes place. The loaded train unit goes back to Musta station. The distance between the stations is $44.7 \mathrm{~km}$. There are four stations which prolong the transportation time in the track.

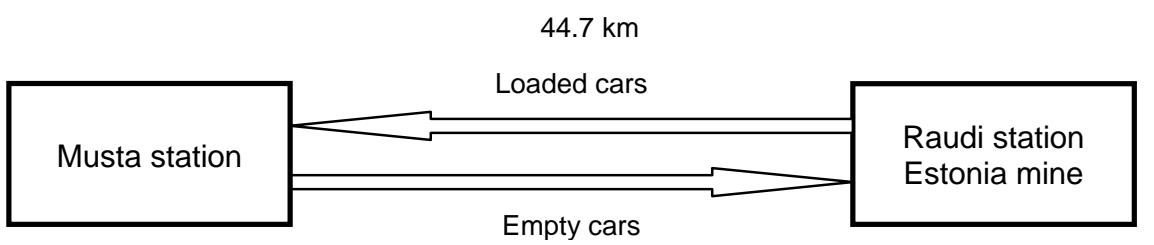

Fig. 3. Network of railways 


\section{Factors contributing to the transport process}

Railroad is a complicated system, the efficiency of railway transport depends on many factors. Some factors relevant to transport processes are presented in Fig. 4.

Main aspects influencing the efficiency of the transport work concern the duration of the processes. Empty and loaded run, loading and waiting processes are the most important factors. It is reasonable to perform the analysis of the transport processes during two weeks. Investigations have shown that duration of the processes differs on a large scale (Table 1).

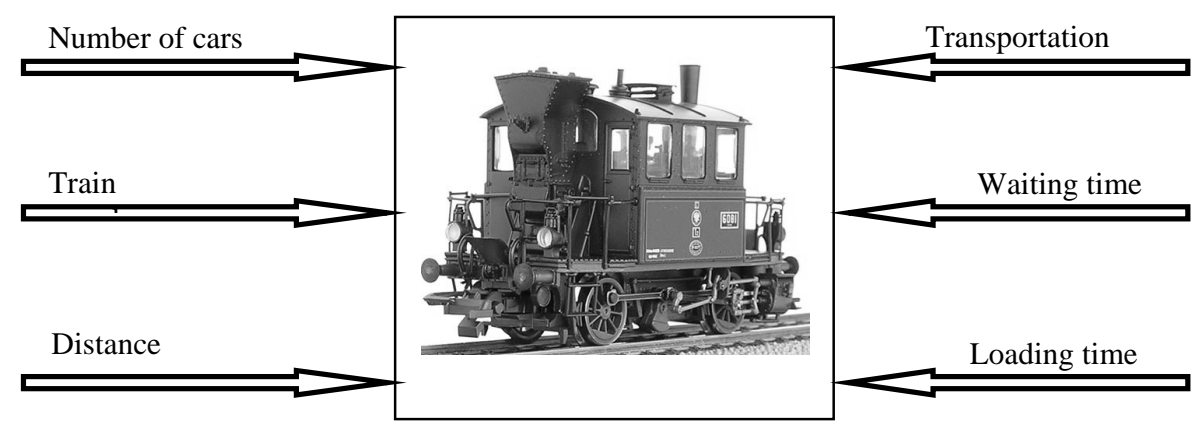

Fig. 4. Factors contributing to the transport process

Table 1. Duration of the process

\begin{tabular}{|l|c|c|c|}
\hline \multirow{2}{*}{ Process } & \multicolumn{3}{|c|}{ Duration of the process, $\mathrm{h}$} \\
\cline { 2 - 4 } & Average & Minimum & Maximum \\
\hline Empty run (Musta-Estonia) & 3.5 & 2.2 & 8.2 \\
Loading & 2.8 & 1.5 & 5.0 \\
Waiting & 1.3 & 0.2 & 4.2 \\
Loaded run (Estonia-Musta) & 3.5 & 2.0 & 5.3 \\
\hline Total & 11.1 & 5.9 & 22.7 \\
\hline
\end{tabular}

\section{Results}

The main quantitative approach used in risk analysis/assessment is the fault/event tree method. This method was selected as the most appropriate one for the analysis/assessment of the risk of the railroad transport system. In the first stage of the project time factor was taken into consideration. For probability determination the empirical approach was used. It utilizes the existing data to generate probable estimates based on historical frequencies. 
Figure 5 presents the event tree for oil shale transport processes indicating the probabilities of the transport processes and spent time. It is possible to select different pathways and to determine the probability of one. Fulltime probability in the event tree is settled by "OR gate" [5,6]. It requires the independence of these factors. It means that the sum of the probabilities of these pathways gives us the total probability.

Figure 6 presents the fault tree that allows to determine time deviations from the mean value. Zero is taken as the mean value of the time. Minus before numbers indicates a decrease in the value, plus - an increase. The sum of the selected pathways determines the full-time deviation from the mean value.

Application of the event and fault trees is presented in Table 2. For instance, two different pathways are considered (variants A and B).

Selected pathways give different value of the probabilities and deviations from the mean value. One can see that the probability of selected pathways is 0.27 (variant $\mathrm{A}$ ) and 0.30 (variant $\mathrm{B}$ ), and deviation from the mean value is 0.13 and 0.12 , respectively. The weight of each process in the full transport cycle is shown. Having this information, a specialist can come to an adequate decision and improve the quality of railway transport between the stations Musta and Raudi (Estonia mine).

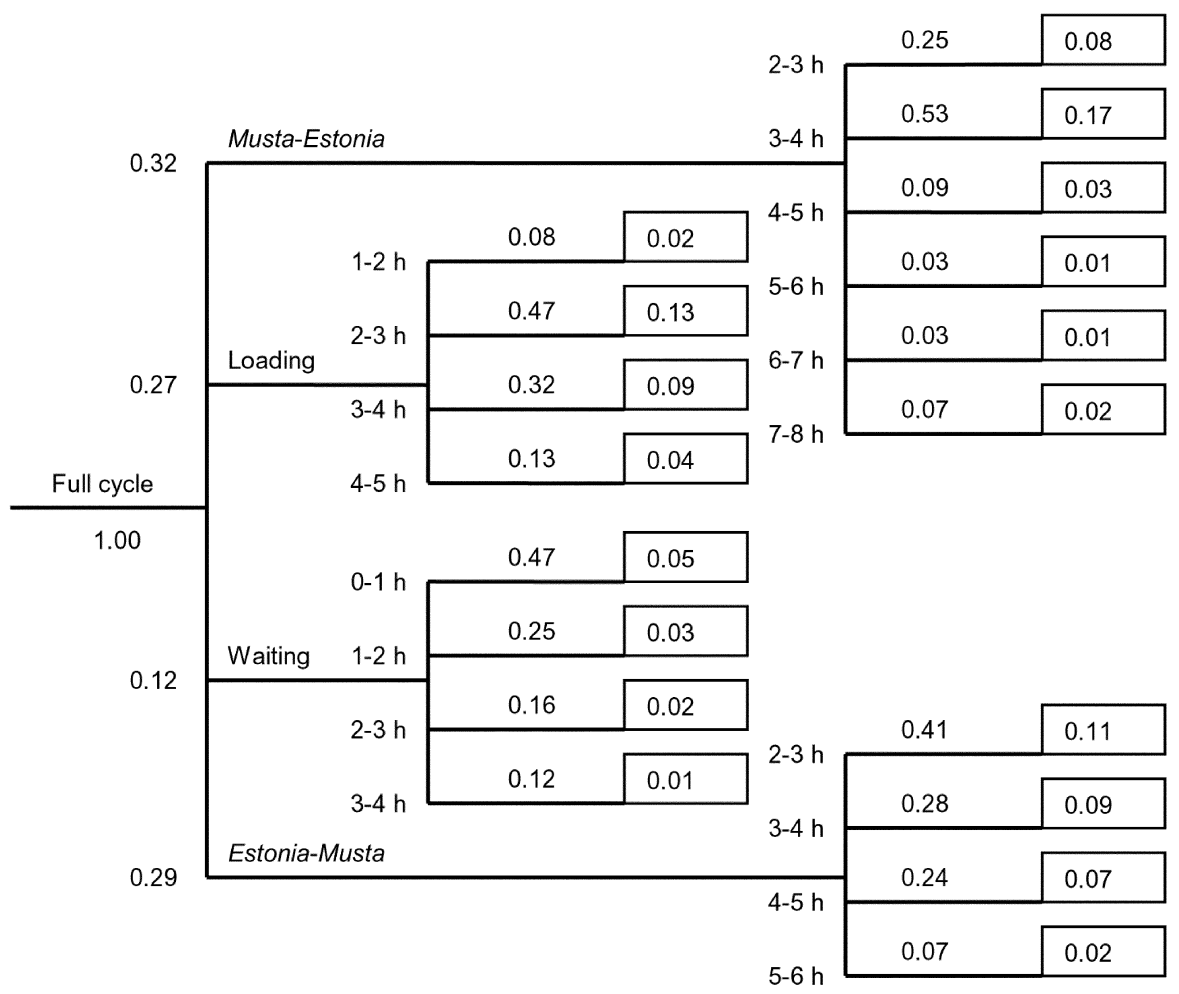

Fig. 5. Event tree 


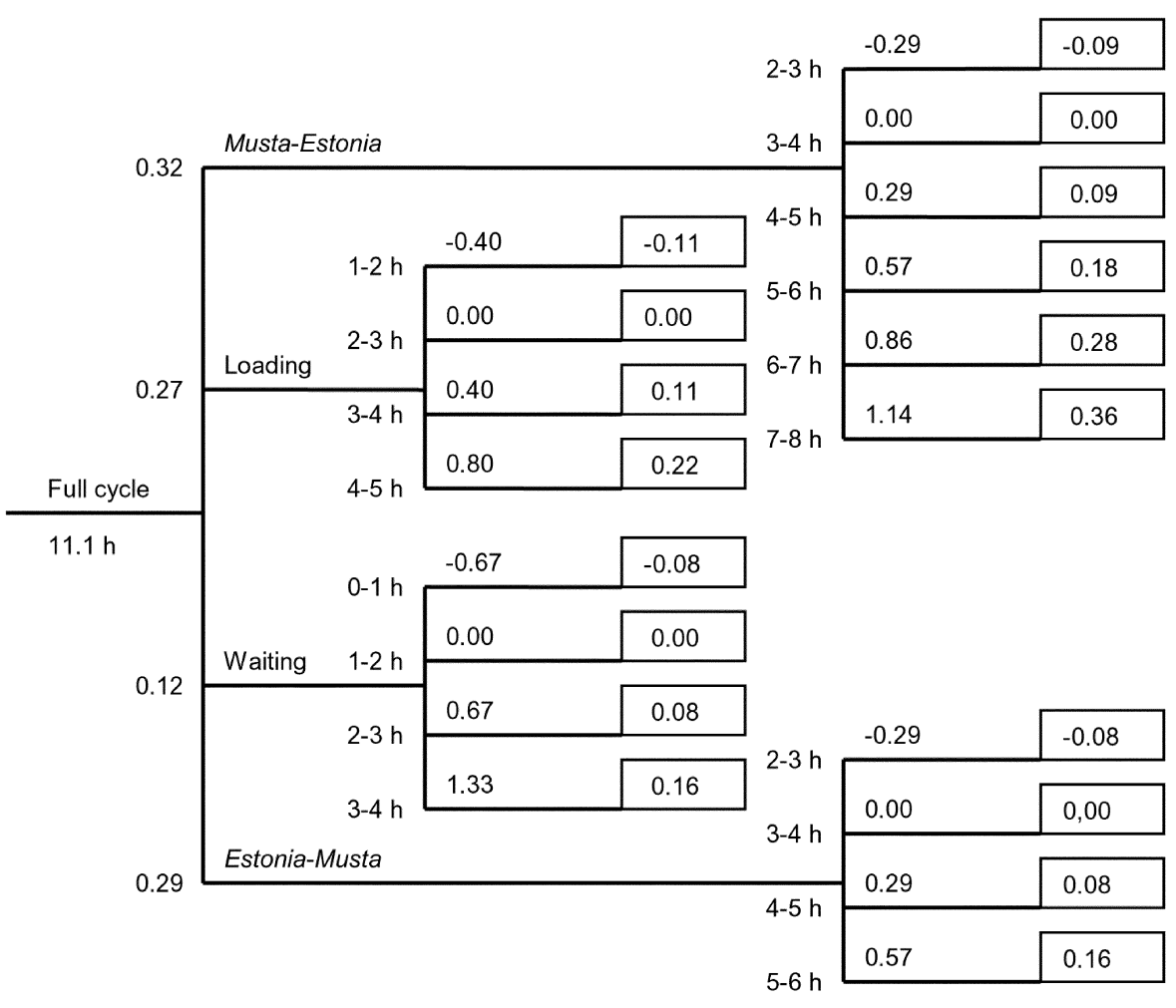

Fig. 6. Fault tree

Table 2. Example of the use of the event and fault trees (Figures 5 and 6)

\begin{tabular}{|l|c|c|c|c|c|c|}
\hline \multirow{2}{*}{ Process } & \multicolumn{2}{|c|}{ Selected time, $\mathrm{h}$} & \multicolumn{2}{c|}{ Event tree } & \multicolumn{2}{c|}{ Fault tree } \\
\cline { 3 - 7 } & \multicolumn{2}{|c|}{$\begin{array}{c}\text { Pathway } \\
\text { probabilities }\end{array}$} & $\begin{array}{c}\text { Deviation from } \\
\text { the mean value }\end{array}$ \\
\cline { 2 - 7 } & \multicolumn{2}{|c|}{ Variant } & \multicolumn{2}{c|}{ Variant } & \multicolumn{2}{c|}{ Variant } \\
\cline { 2 - 7 } & $\mathrm{A}$ & $\mathrm{B}$ & $\mathrm{A}$ & $\mathrm{B}$ & $\mathrm{A}$ & $\mathrm{B}$ \\
\hline Empty run (Musta-Estonia) & $3-4$ & $6-7$ & 0.17 & 0.01 & 0.00 & 0.28 \\
Loading & $1-2$ & $2-3$ & 0.02 & 0.13 & -0.11 & 0.00 \\
Waiting & $3-4$ & $0-1$ & 0.01 & 0.05 & 0.16 & -0.08 \\
Loaded run (Estonia-Musta) & $4-5$ & $2-3$ & 0.07 & 0.11 & 0.08 & -0.08 \\
\hline Total & - & - & 0.27 & 0.30 & 0.13 & 0.12 \\
\hline
\end{tabular}

It may be concluded that the applied methods give excellent results. They are suitable to perform the investigations for the network of railways on the tracks between the mines and open pits belonging to Estonian Oil Shale Company and consumers. 


\section{Conclusions}

As a result of this study, the following conclusions and recommendations can be made:

1. In Estonia oil shale is the most important mineral resource. Railway transportation of oil shale is indispensable. Transportation of oil shale from mines and open casts to consumer by railway causes a lot of technical, economical, ecological and juridical problems.

2. The present study addresses the risk associated with transportation time. The primary interest of this study concerns evaluation of the usability of the method and evaluation of the probability of transportation time without a detailed assessment of the consequences.

3. Various factors relevant to transport have been determined. The event tree determines the probability of the efficiency of the transport system. The fault tree gives information about the deviation of the transport time from its mean value.

4. The risk analysis/assessment method is a powerful tool to solve complicated problems in the railway transport. The analysis shows that the used methods are applicable in conditions of Estonian railway systems. The results of the investigation are of particular interest for practical purposes.

5. Basing on the excellent results of this investigation, it is recommended to use the applied methods for the whole network of railways from mines and open casts to consumers.

\section{Acknowledgments}

Estonian Science Foundation (Grant No. 6558, 2006-2009) supported the research.

\section{REFERENCES}

1. Calow, P. Handbook of Environmental Risk Assessment and Management. Oxford, Blackwell Science, 1998.

2. Hoeg, $K$. Performance evaluation, safety assessment and risk analysis for dams // Hydropower \& Dams. 1996. No. 6. P. 47-63.

3. Lind, H. G. Mitigating the risk associated with underground coal pillar extraction in South Africa // Mining Technology. Transaction of the Institutions of Mining and Metallurgy. 2004. Vol. 113, No. 4. P. 215-224.

4. Rowe, E. D. Risk Assessment Approaches and Methods // Society, Technology and Risk Assessment / J. Conrad (ed.). London: Academic Press, 1980. P. 3-29. 
5. Williams, D. J., Loch, R. J., Vacher, C. Risk assessment applied to tunnel erosion of mine spoils // Proc. of the $11^{\text {th }}$ Tailings and Mine Waste Conference. 10-13 October 2004, Vail, Colorado, USA, 2004, P. 63-70.

6. Rail safety research // Collection of the research reports. 1992-2005. www.railreg.gov.uk/server/show/nav.1184.

Presented by E. Reinsalu

Received May 25, 2006 